\title{
Cumplimiento de términos en la tramitación de la acción de protección
}

The breach of terms in the processing of the protection action

\author{
Mariuxi Yolanda Correa-Cordero \\ mariuxi.correa@psg.ucacue.edu.ec \\ Universidad Católica de Cuenca, Cuenca \\ Ecuador \\ https://orcid.org/0000-0001-8283-2529 \\ Cecilia Ivonne Narváez-Zurita \\ inarvaez@ucacue.edu.ec \\ Universidad Católica de Cuenca, Cuenca \\ Ecuador \\ https://orcid.org/0000-0002-7437-9880 \\ Juan Carlos Erazo-Álvarez \\ jcerazo@ucacue.edu.ec \\ Universidad Católica de Cuenca, Cuenca \\ Ecuador \\ https://orcid.org/0000-0001-6480-2270 \\ Enrique Eugenio Pozo-Cabrera \\ epozo@ucacue.edu.ec \\ Universidad Católica de Cuenca, Cuenca \\ Ecuador \\ https://orcid.org/0000-0003-4980-6403
}

Recibido: 11 de abril de 2020

Revisado: 13 de mayo de 2020

Aprobado: 24 de mayo de 2020

Publicado: 14 de junio de 2020 


\title{
RESUMEN
}

En Ecuador se evidencia el incumplimiento de los términos en el procedimiento de la acción de protección por parte de los jueces constitucionales, por consiguiente, se planteó diseñar un protocolo que garantice el cumplimiento de los términos en el procedimiento de la acción de protección. Para este propósito se aplicó un estudio con alcance descriptivo. se concluye que existe incumplimiento de los términos en la tramitación de la garantía jurisdiccional antes indicada; y, de este modo se vulneran de forma directa los derechos constitucionales de la tutela efectiva y del debido proceso, puesto que las diferentes actividades procesales tienen un retraso demasiado elevado con referencia a los términos que se plantean en la LOGJCC. Por consiguiente, no se está dando la protección debida a los derechos de las personas conforme lo manda la constitución y los tratados internacionales de derechos humanos.

Descriptores: Procedimiento legal; derecho a la justicia; derechos humanos; constitución. (Palabras tomadas del Tesauro UNESCO).

\begin{abstract}
In Ecuador, the breach of the terms in the protection action procedure by the constitutional judges is evident, therefore, it was proposed to design a protocol that guarantees compliance with the terms in the protection action procedure. For this purpose, a study with a descriptive scope was applied. It is concluded that there is a breach of the terms in the processing of the jurisdictional guarantee indicated above; and, in this way, the constitutional rights of effective guardianship and due process are directly violated, since the different procedural activities have too high a delay with reference to the terms set forth in the LOGJCC. Consequently, due protection of the rights of individuals is not being given as mandated by the constitution and international human rights treaties.
\end{abstract}

Descriptors: Legal procedure; right to justice; human rights; constitution. (Words taken from the UNESCO Thesaurus).

\section{INTRODUCCIÓN}

En el Ecuador se realizaron un sin número de reformas a la Constitución, sin embargo, en el nuevo texto constitucional del 2008 existió un mayor cambio; puesto que fue con referéndum que se incluyó en este cuerpo normativo a la acción de protección, garantía 
que no solo se aplica al ámbito jurisdiccional, sino que incluye a la administración pública y derechos constitucionales, dando origen de esta manera a los tres tipos de garantías que se establecen en dicho cuerpo normativo. El nuevo diseño de la justicia constitucional en el Ecuador, tiene como objetivo principal el cuidado y defensa de los derechos humanos mediante un sistema garantista, que cuenta con mecanismos o instrumentos que permiten evitar la vulneración de derechos o reparar las violaciones cuando estas ya han producido daño (Montaña \& Porras, 2012).

Para analizar la problemática se debe mencionar que de acuerdo a la Ley Orgánica de Garantías Jurisdiccionales y Control Constitucional (LOGJCC), la acción de protección como garantía jurisdiccional, tiene por "objeto el amparo directo y eficaz de los derechos reconocidos en la Constitución y tratados internacionales sobre derechos humanos(...)" (Asamblea Nacional , 2009, art. 39) que no estén amparados por las otras garantías constitucionales instituidas en la legislación; es un proceso rápido, simple, no requiere de formalidades y no es indispensable citar el derechos vulnerado; por lo que en su procedimiento se disponen términos que al no ser aplicados de la forma establecida generaran dilaciones innecesarias, alejándose de la finalidad de esta garantía constitucional.

Esta problemática surgida a raíz del incumplimiento de los términos en el procedimiento de la acción de protección, es de interés social ya que existen violaciones procesales en las que están incurriendo los jueces constitucionales, al no aplicar los términos establecidos en la aceptación a trámite, convocatoria a audiencia, emisión de sentencia y en el trámite que se realiza en segunda instancia, inobservando de esta forma los derechos reconocidos en la constitución.

La actual investigación se refiere a la garantía jurisdiccional de la acción de protección, denominada en la constitución del año 1998 como recurso de amparo constitucional (Asamblea Nacional Constituyente, 1998); que se utilizaba como un instrumento para salvaguardar los derechos reconocidos en la constitución, que eran quebrantados, amenazados o vulnerados.

Atendiendo estas consideraciones, ha surgido el siguiente problema de investigación: ¿El 
incumplimiento de los términos en el procedimiento de la acción de protección vulnera el derecho al debido proceso y tutela efectiva? Dentro de este marco, es ineludible determinar el objetivo general, el mismo que consiste en diseñar un protocolo que garantice el cumplimiento de los términos en el procedimiento de la acción de protección, dirigido a Jueces con competencia en materia constitucional en el Ecuador que permita asegurar el derecho al debido proceso y tutela efectiva.

\section{Referencial teórico}

\section{El debido proceso y la tutela efectiva en la acción de protección}

El derecho a un proceso justo es el resultado de un sinnúmero de luchas y reformas que han obtenido las personas a lo largo de la historia, imponiéndose a los poderes políticos, ilegalidades y arbitrariedades tanto en el ámbito público como privado, constituyéndose en un limitante judicial para quienes no respetan la normativa vigente. Según (Jaramillo, 2014) a partir de la Constitución del 2008, entre los derechos de protección, se encuentran el debido proceso establecido en el Art. 76, el mismo que dispone que toda persona tenga derecho a ciertas garantías mínimas y al mismo tiempo obliga a los operadores de justicia a aplicarlo en el desarrollo de los procesos, por lo que se deduce que el debido proceso no es más que una herramienta que permite a los titulares de derechos, exigir que el desarrollo del proceso judicial se realice conforme a los procedimientos incorporadas en la Constitución y la ley.

En ese mismo contexto, (Storini, 2017) manifiesta que el debido proceso es un limitante a las actuaciones de las autoridades públicas. El debido proceso permite que las actuaciones de los jueces estén ajustadas a las normas y procedimientos establecidos en la constitución y las leyes vigentes. Al ser incorporado el debido proceso en la CRE, por ser una norma suprema las normas secundarias deben estar sujetas a ella, por lo tanto, es de observancia obligatoria para todo el sector público, ya que deberá ser acatado en todas las funciones y procesos incluyendo los administrativos. En líneas generales, todos los organismos que pertenecen a las funciones del Estado y el sector público están en la obligación de aplicar y cumplir con las normas previstas en la 
constitución y que puedan ser reclamadas en la justicia ordinaria.

Según (Gray, 2000), las reglas incorporadas en la Constitución y en los instrumentos internacionales tienen carácter procesal, y están dirigidas a los diferentes poderes del Estado. Asimismo, (Storini, 2017) indica que el debido proceso, se lo entiende como el derecho que rige los procesos judiciales en un Estado constitucional; resaltando que exige el cumplimiento de reglas mínimas en el desarrollo de los procesos. En ese mismo contexto, sostiene que el debido proceso tiene dos dimensiones: la subjetiva que es ejercida por el titular del derecho; y la objetiva, en la que se imponen los límites a la labor legislativa, ejecutiva y judicial.

Cabe considerar, por otra parte que la LOGJCC en el artículo 4 instaura principios procesales, de los cuales el debido proceso y la economía procesal configuran las reglas de: la concentración, la celeridad, publicidad, iura novit curia, subsidiariedad (Asamblea Nacional, 2009). De este modo, se determina que en todo proceso se deben observar de forma rigurosa las garantías del debido proceso para lograr una sustanciación justa basada en el cumplimiento de normas preestablecidas en el ordenamiento jurídico.

Por consiguiente, se debe analizar la tutela efectiva, considerada como derecho constitucional que tiene una persona para concurrir ante un juez independiente, imparcial y competente con el fin de solicitar protección jurídica real, integra y rápida, en aras de recibir la solución y reparación al derecho constitucional vulnerado. Al respecto, (Jaramillo, 2014) manifiesta que el acceso a la justicia como derecho tiene estrecha relación con la tutela efectiva, imparcial y expedita; lo cual permite que se cumplan con las normas y principios constitucionales dentro de un proceso judicial. De esta manera, se puede deducir que la tutela efectiva permite a los titulares de los derechos acceder a la justicia ordinaria sin ningún tipo de restricciones que puedan entorpecer el reclamo justo de la vulneración a la que haya sido sujeto.

La Corte Constitucional ecuatoriana realiza un análisis al derecho a la tutela judicial efectiva, en la cual concluye que este derecho no se termina con el acceso simple a un proceso judicial; por el contrario, exige el cumplimiento de la garantía al debido proceso (Sentencia 292-SEP-CC., 2016). Dicho de otro modo, no existe una verdadera tutela sino 
se aplican los parámetros prescritos en el ordenamiento interno, los mismos que permiten que el desarrollo del proceso judicial sea sin dilaciones innecesarias. En este mismo escenario, la Corte señala que la tutela efectiva tiene tres momentos: el acceso a la justicia ordinaria, las actividades alineadas a disposiciones constitucionales y el cumplimiento de los derechos reparados (Sentencia 364-16-SEP-CC., 2016). En consecuencia, para la aplicación efectiva de este derecho se requiere que la persona que haya sufrido la vulneración de un derecho debe activar la justicia constitucional conforme las reglas establecidas y ante la autoridad jurisdiccional correspondiente, quien deberá garantizar el restablecimiento del derecho vulnerado.

\section{Acción de protección en tratados y convenios internacionales, sistemas regionales y su origen en la legislación ecuatoriana}

La Declaración Universal de Derechos Humanos aprobada en el año 1948 en su cuerpo normativo instaura que a todo individuo se le garantizará el acceso a un proceso eficaz y obliga a los Estados parte a su implementación (Asamblea General de las Naciones Unidas, 1948). Debe señalarse, que la Declaración Americana de los Deberes y Derechos del Hombre establece en su art. 18 que todas las personas pueden recurrir a la justicia para exigir sus derechos fundamentales mediante un procedimiento sencillo y breve (IX Conferencia Internacional Americana, 1948); en este mismo contexto, la Organización de Estados Americanos, a través de su Convención del año 1969, en el Art. 25 al referirse a la protección judicial, estable que al existir vulneración de derechos fundamentales reconocidos en diferentes cuerpos normativos, los ciudadanos cuentan con el derecho a un litigio simple, sumario y eficaz ante la autoridad competente (Organización de los Estados Americanos, 1969).

La legislación comparada, como su nombre lo indica permite comparar las leyes internas que establece cada país para ver la similitud o diferencia en temas jurídicos específicos; por lo que, la acción de protección como se conoce en Ecuador tiene diferentes nombres en los países de la región. De acuerdo con un breve análisis de los Estados que 
contemplan a la garantía de protección en el ordenamiento jurídico interno son: a) el recurso de protección establecido en el art. 20 de la Constitución de Chile, calificada como una acción jurisdiccional que busca el resguardo del afectado ante actos ilícitos, negligentes o injustos que vulneren los derechos humanos (Ministerio Secretaria General de la Presidencia, 1980); b) en la República del Perú, la acción de amparo es un proceso constitucional que se lo activa al momento de verificarse la vulneración de derechos que por ley son inherentes a las personas, ya sea por cualquier órgano estatal o personas particulares (Congreso Constituyente Democrático, 1993); c) la acción de tutela en Colombia, estipula que cualquier persona cuando considere que sus derechos constitucionales fundamentales han sido quebrantados o amenazados por cualquier acción u omisión de autoridad pública, pueden acceder a un procedimiento inmediato para reclamar sus derechos; asimismo, establece que entre la petición de tutela y la resolución del juez no pueden trascurrir más de 10 días (Asamblea Nacional Constituyente, 1991); y, d) en Bolivia, la acción amparo constitucional, va en contra de funcionarios públicos, persona individual o colectiva que con acciones u omisiones limitan o afectan derechos legítimos de las personas (Asamblea Constituyente de Bolivia, 2009).

En el Estado ecuatoriano, esta garantía tuvo sus inicios en la legislación de 1967, con el nombre de amparo jurisdiccional, establecido en el numeral 15 del artículo 28, el mismo que prescribía que toda persona pueda demandar contra cualquier violación a las garantías jurisdiccionales (Asamblea Nacional Constituyente, 1967). Se realizaron un sin número de reformas, hasta que el 10 de agosto de 1998, se integra al ordenamiento jurídico ecuatoriano a la acción de amparo jurisdiccional, con algunas innovaciones en beneficio de los derechos de las personas, contemplada en el Art. 95 (Asamblea Nacional Constituyente, 1998). Se hace imperioso señalar que pese a las diferentes reformas constitucionales que se han desarrollado en el Ecuador, las Constituciones desde 1948 han respetado los derechos establecidos en los instrumentos internacionales.

Un giro transcendental se verificó con la elaboración del nuevo texto constitucional que fue aprobado por la Asamblea Constituyente mediante referéndum, en el que se 
incorporó a la acción de protección como garantía constitucional. Es así que, la Constitución (Asamblea Nacional Constituyente, 2008) establece que esta garantía será activada cuando se verifique la vulneración de derechos, con la finalidad de obtener su tutela inmediata, vulneraciones que pueden ser ocasionadas por hechos o negligencias de autoridades públicas no judiciales, empresas públicas o personas particulares en la prestación de servicios.

La LOGJCC en el artículo 39 señala que: la acción de protección tendrá los mismos parámetros que establece el texto constitucional o instrumentos internacionales que protejan los derechos de las personas que no se prevea su protección en otros procedimientos ordinarios (Asamblea Nacional, 2009). Es decir, se puede considerar como un mecanismo procesal que permite auxilio y protección de los derechos constitucionales. Al respecto, se debe indicar que la Corte Constitucional de forma clara indica que la LOGJCC y en la Constitución de la República tienen una misma perspectiva normativa, puesto que las dos instituciones jurídicas tienen la finalidad de protección inmediata y efectiva de los derechos humanos reconocidos tanto en la normativa nacional como internacional (Sentencia 204-12-SEP-CC., 2012). Cabe considerar, por otra parte, la opinión de (López, 2018) quien manifiesta que mediante la acción de protección también se subsana conflictos, esto cuando existe una conducta dañosa que amenace, perturbe o prive un derecho constitucional.

Así mismo, se considera que es una acción reparatoria, por cuanto logra la reparación integral del daño causado, a través del proceso judicial en el cual se observen las garantías mínimas en su tramitación y el juez que declare la vulneración del derecho está en la obligación de velar por el resarcimiento del daño causado, es decir, volver el derecho al estado anterior (Montaña \& Porras, 2012). De igual manera, ArichavalaZúñiga; Narváez- Zurita; Guerra-Coronel; Erazo-Álvarez (2019) manifiestan respecto de la acción de protección que: "(...) también forma parte de su naturaleza propia la reparación integral de la víctima, teniendo como resultado una verdadera tutela" (p.167). En la jurisprudencia de la Corte Constitucional del Ecuador se señala que la autoridad jurisdiccional que conozca de una acción de protección, luego de su análisis de fondo y 
de forma, está obligado a declarar la vulneración del derecho y ordenar de manera inmediata en la misma sentencia la reparación integral (Sentencia 080-13-SEP-CC., 2013). Los conceptos antes mencionados se complementan con la opinión de (BravoNúñez, Narváez-Zurita, Vázquez-Calle, \& Erazo-Álvarez, 2020) referente a la reparación integral que expresa que es obligación de los operadores de justicia ordenar la reparación integral, por encontrarse establecida de manera expresa en la norma suprema. Según la Constitución del 2008, la acción de protección es directa y eficaz, para proteger los derechos reconocidos; no obstante, también rescata que dicha acción es sencilla, rápida, eficaz.

Con las definiciones e ideas expuestas en párrafos anteriores, se puede perfilar a la acción de protección como universal, informal, inmediata y reparadora. Sin dejar de lado el análisis que realiza (Calle, 2010) sobre las características de la misma garantía, considerándola como directa, preferencial, sumaria y oral. (Quintana, 2016) en esa misma línea, la determina con las siguientes características: naturaleza constitucional, constituye un proceso de conocimiento, es tutelar, es reparatoria, no es subsidiaria ni residual.

\section{Procedimiento, competencia y tipos de legitimación}

La Constitución ecuatoriana en el art. 86.2, señala que la competencia para que el juez conozca la acción de protección se determinara por el lugar donde se originó la vulneración del derecho 0 donde se producen sus efectos (Asamblea Nacional Constituyente, 2008). De igual manera la LOGJCC en el art. 7, se ajusta a lo prescito en la constitución, ya que establece que la autoridad competente, será el juez de primera instancia en donde se generó la vulneración del o de los derechos constitucionales o en el lugar donde se produzcan sus efectos (Asamblea Nacional, 2009). Será el accionante quien considere cual de las dos autoridades deberá conocer la petición, sin que ello determine su beneficio en la contienda legal.

La persona o grupo de personas, comunidad, pueblo o nacionalidad que presente ante 
un juez constitucional, la petición para reclamar la vulneración de un derecho se denomina legitimación activa (Asamblea Nacional Constituyente, 2008); así lo determina la Constitución, permitiendo que quienes se vean vulnerados en sus derechos puedan acudir a la justicia constitucional de forma individual y colectiva. Al respecto, (Ávila, 2012) manifiesta que todos los derechos humanos tienen doble dimensión, una individual y otra colectiva, lo que permite que si un individuo se considera vulnerado puede acudir de manera personal o a nombre de un colectivo o grupo de personas para reclamar sus derechos constitucionales. De igual manera, (Quintana, 2016) considera que para tener legitimación activa al ejercer una garantía constitucional deben ser los afectados directos o indirectos del derecho vulnerado, ya sea por acto u omisión quienes presenten el reclamo. La Jurisprudencia de la Corte Constitucional, ha manifestado que toda persona o grupo de personas podrán presentar las acciones constitucionales (Sentencia 06-10SAN-CC., 2010).

De acuerdo con análisis realizado la legitimación pasiva corresponde al autor del acto que vulnera un derecho fundamental. Según (Jaramillo, 2014), considera que la legitimación pasiva se la encuentra en los siguientes eventos: a) cuando la transgresión del derecho proceda de un funcionario público no judicial; b) contra Políticas Públicas que limiten un derecho fundamental; c) cuando la vulneración sea ocasionada por actos u omisiones de personas naturales o jurídicas privadas.

La admisibilidad en las garantías constitucionales son conjunto de requisitos o exigencias legales que se establecen para presentar una acción constitucional; es decir, son formalidades que se deben cumplir en la petición que se realiza ante la autoridad competente, para solicitar la protección del derecho vulnerado. Por otro lado, se debe distinguir la procedibilidad, la misma que consiste en el análisis de fondo que efectúa el juez previo a aceptar o negar la acción. La Corte Constitucional, ejecuta un análisis y señala que los requisitos para la admisibilidad de la acción de protección se encuentran establecidos en el Art. 40 y son: 1) quebrantamiento de un derecho humano; 2) ejercicio o descuido de autoridades públicas o de un particular; 3 ) falta de procedimiento judicial 
adecuado que proteja el derecho vulnerado (Sentencia 102-13-SEP-13., 2013).

Dentro de las 24 horas siguientes de presentada la demanda el Juez deberá calificarla y aceptarla a trámite de reunir los requisitos tanto de forma y de fondo establecidos en líneas anteriores. En este mismo auto de aceptación, se deberá realizar la convocatoria a audiencia pública la cual que no deberá ser establecida en un término mayor a 72 horas (Asamblea Nacional, 2009). Se debe tener en cuenta que en las garantías constitucionales son hábiles todos los días y horas, incluyendo sábados, domingos y feriados (Sentencia 045-13-SEP-13., 2013).

En la etapa probatoria, el accionante tiene la posibilidad de evidenciar los hechos mediante los cuales se pueda demostrar la vulneración del derecho alegado en su petición inicial. Se debe indicar que cuando se origine la vulneración de derechos en contra del Estado o particulares -discriminación, naturaleza y medio ambiente- la carga de la prueba se invierte. Además, es necesario recalcar que el Juez está en la facultad de solicitar los medios probatorios que coadyuven a una mejor decisión, para lo cual podrá designar delegaciones para su obtención; prácticas que deberán realizarse en un tiempo no mayor a 8 días y por una sola vez, siempre y cuando no se afecte el proceso justo o cause retraso injustificado para su resolución (Asamblea Nacional, 2009).

En la legislación ecuatoriana existen 3 escenarios para dar por terminado un proceso de garantía jurisdiccional, entre están: el desistimiento que involucra dos situaciones, la primera que es la inasistencia a la audiencia por parte de la accionante y que se lo considera como desistimiento tácito, y segundo el desistimiento expreso que es cuando él o la accionante renuncia a la acción por razones personales que deberán ser estimadas por el juez. Se considera el allanamiento, cuando la parte accionada acepta y reconoce la vulneración del derecho, y este puede ser parcial o total; de ser parcial se continuará con el procedimiento. Y como último escenario está la sentencia, la misma que debe dictarse de forma verbal dentro de la audiencia pública y notificarse en las 48 horas siguientes a las misma (Asamblea Nacional, 2009). 


\section{MÉTODO}

El tipo de investigación que se realizó en el presente artículo fue transversal con un carácter descriptivo, por cuanto se partió del análisis del derecho a un proceso justo y una defensa eficaz, así como también se realizó un estudio a la acción de protección, desde su conceptualización hasta la tramitación de la garantía constitucional con base a la legislación ecuatoriana. La información obtenida se recopiló de diferentes fuentes: libros, revistas jurídicas, constitución, leyes, sentencias y artículos publicados en revistas científicas indexadas.

Para el análisis de los datos se utilizó un enfoque mixto, predominando en el método cualitativo que permitió realizar la revisión documental y estudio de los conceptos, generalidades y teorías relacionas con el derecho a un proceso justo y una defensa eficaz, así como analizar a la acción de protección desde sus inicios, su vigencia en los tratados internacionales, en sistemas regionales hasta precisar el estudio del procedimiento de la acción de protección (admisión y procedibilidad, audiencia, prueba, sentencia). Así mismo, se realizó una investigación empírica mediante el análisis de causas (acciones de protección) ingresadas en el primer semestre del 2019 en una Unidad Judicial de Loja. Además, se aplicó la técnica cuantitativa a través de la estadística inferencial, mediante la cual se logró la tabulación de datos obtenidos en la aplicación de encuestas a abogados en libre ejercicio.

Los métodos aplicados en esta investigación jurídica fueron: el método histórico - lógico que se enfocó en revisar la evolución de la acción de protección hasta la actualidad, a través del estudio de sus conceptos en diferentes constituciones y como complemento en diferente legislaciones; otro de los métodos aplicados es el analítico - sintético que sirvió para explicar aspectos generales del derecho a un proceso razonable y justo hasta su alcance en materia constitucional; así mismo se aplicó el método inductivo - deductivo que permitió exponer aspectos generales de los derechos constitucionales en estudio a partir de su conceptualización hasta determinar su vinculación con la acción de protección. 
En la investigación se aplicó un muestreo por conveniencia, el mismo que se sustentó en una técnica no probabilística y no aleatoria, por lo que se tomó en consideración los siguientes criterios: profesión, accesibilidad y conocimiento de la materia; en virtud de lo expuesto la muestra estuvo conformada por 21 abogados en libre ejercicio con experiencia en materia constitucional. Además, se aplicó un muestreo de 32 acciones de protección para el análisis de causas referidas en la página del Consejo de la Judicatura.

\section{RESULTADOS}

Realizada la encuesta sobre el incumplimiento de términos en la tramitación de la acción de protección y la afectación al derecho al debido proceso y tutela efectiva y una vez recabada la información, es imprescindible dar un enfoque constitucional a los resultados obtenidos, para analizar el alcance de los derechos vulnerados a través de la efectividad de la acción de protección.

El estudio se lo efectuó con fines académicos y por la materia analizada, se consideró la intervención de abogados en libre ejercicio de su profesión quienes participaron en el levantamiento de información a través de una encuesta, su esquema estuvo estructurado por 12 preguntas con alternativas de respuestas ya establecidas, la misma que fue aplicada a 21 abogados de la ciudad de Loja. El tratamiento y análisis de la información obtenida constituyó el argumento científico para la identificación del problema de estudio. Entre los principales resultados se estableció:

La primera pregunta de la encuesta tenía como finalidad verificar si los profesionales encuestados tienen conocimiento del objeto de la acción de protección, se obtuvo que existe un alto conocimiento en los Abogados encuestados (100\%). Esto permite deducir que los abogados consultados tienen conocimientos en materia constitucional y permitirá obtener respuestas que reflejen la situación procedimental de la acción de protección. Con relación a la pregunta realizada a los profesionales del derecho referente a la importancia del respeto de los términos en la tramitación de la acción de protección, el $76 \%$ de profesionales considera que los tiempos establecidos en la LOGJCC son de alto 
nivel de importancia, mientras que, un $14 \%$ señala que su nivel de importancia es medio y el $10 \%$ restante que su nivel de importancia es bajo (ver figura 1 ), estos resultar permiten evidenciar que el cumplimiento de los términos establecidos en la constitución y la ley son de vital importancia en la tramitación de la acción de protección que permite que esta garantía cumpla con su objeto de ser directa y eficaz ante la vulneración de derechos constitucionales.

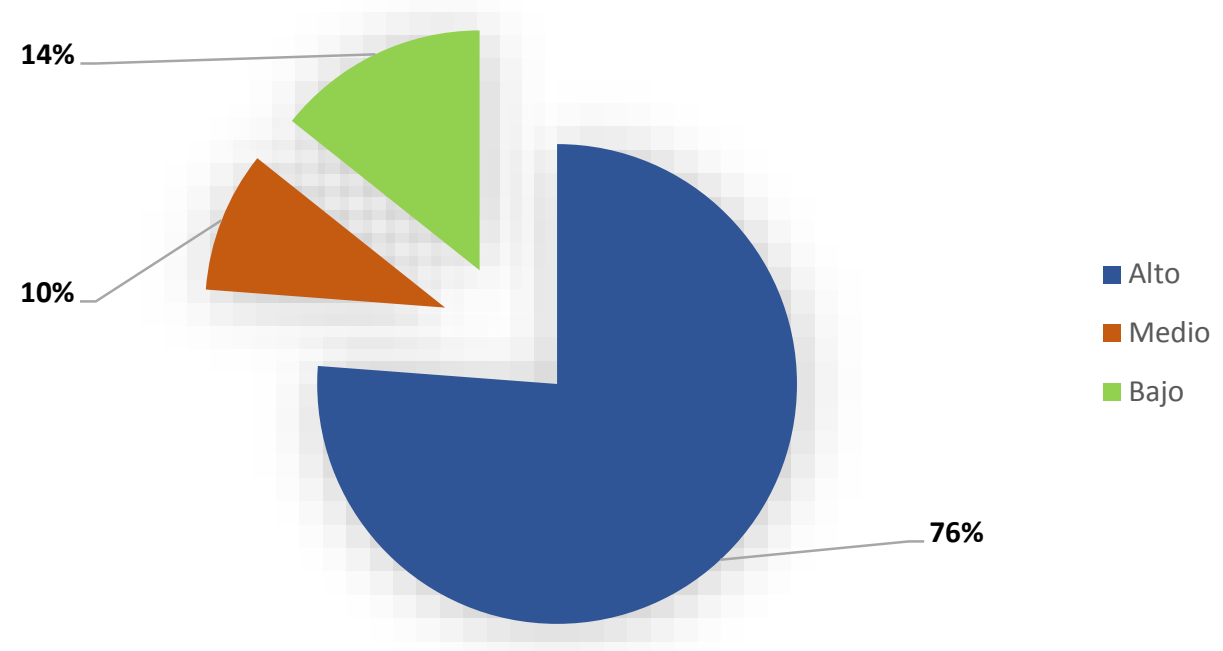

Figura 1. Nivel de importancia de términos en la tramitación de la acción de protección. Fuente. Encuestas realizadas a Abogados en libre ejercicio

Así mismo, al consultarles sobre si la demora en la tramitación de la acción de protección se contrapone al objeto de esta garantía constitucional, el 90\% considera que si, mientras que, el $10 \%$ de encuestados piensa que no. De este análisis, se verifica que los abogados en libre ejercicio no ven efectividad en la acción de protección, por cuanto su característica principal es ser sencilla, rápida y sin dilaciones innecesarias.

En lo referente al conocimiento de la tutela efectiva y debido proceso, el $100 \%$ de los encuestados tienen conocimiento de estos dos derechos constitucionales que son imprescindibles en la tramitación de los procesos, ya que permiten no solo el acceso a la justicia, sino que se observen las garantías mínimas en el desarrollo del proceso.

Sobre la determinación de si se cumplen o no los términos en la tramitación de la acción 
de protección, se observó que el $62 \%$ de la unidad de análisis considera que rara vez se cumplen los términos en la garantía constitucional de la acción de protección; y tan solo el $9 \%$ afirma que nunca se cumplen, a diferencia del $29 \%$ de encuestados que estiman que siempre se aplican los términos procesales (ver figura 2). De las evidencias obtenidas se establece que la tramitación de la acción de protección no se cumple en su totalidad los términos procesales establecidos en la LOGJCC lo que ocasiona que la vulneración del derecho no sea tutelada de manera oportuna.

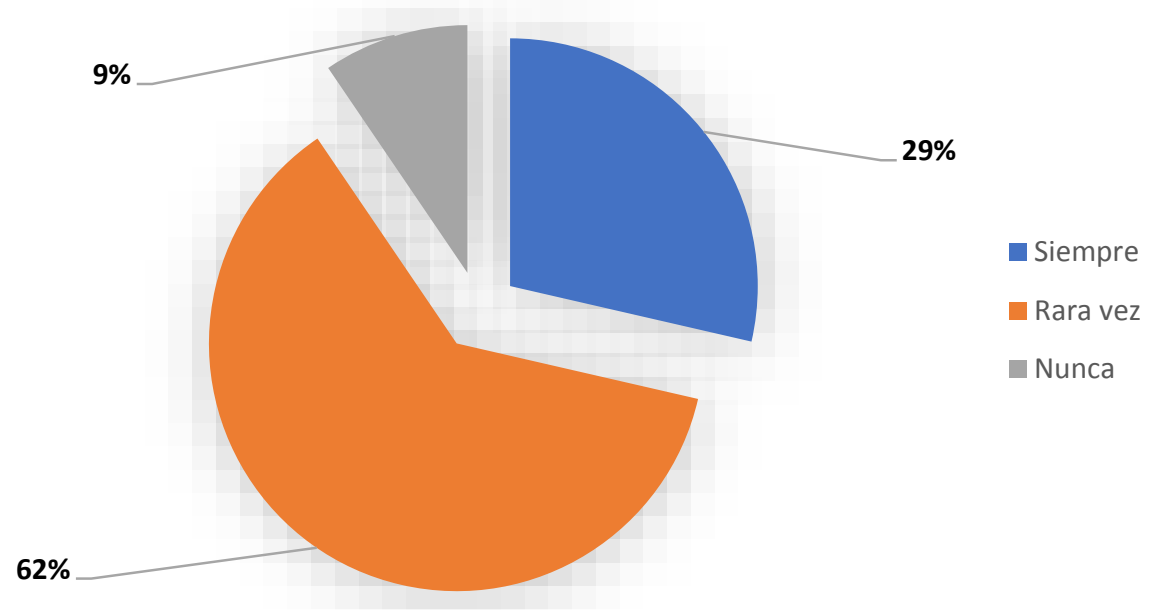

Figura 2. Cumplimiento de los términos en la tramitación de la acción de protección. Fuente. Encuestas realizadas a Abogados en libre ejercicio.

Se consultó si es indispensable la elaboración de un protocolo con la finalidad de lograr el cumplimiento de términos y el amparo eficaz de los derechos vulnerados en la acción de protección; obteniendo que el $90 \%$ considera que, si se debe realizar un protocolo para tramitación de la acción de protección, mientras que, un $10 \%$ indican que no es necesaria su elaboración (ver figura 3). De las evidencias obtenidas se establece que si es necesario desarrollar un protocolo de tramitación que permita que la garantía jurisdiccional sea un instrumento efectivo para la protección de derechos establecidos en la constitución y en tratados internacionales; dentro del marco del debido proceso y la tutela efectiva. 


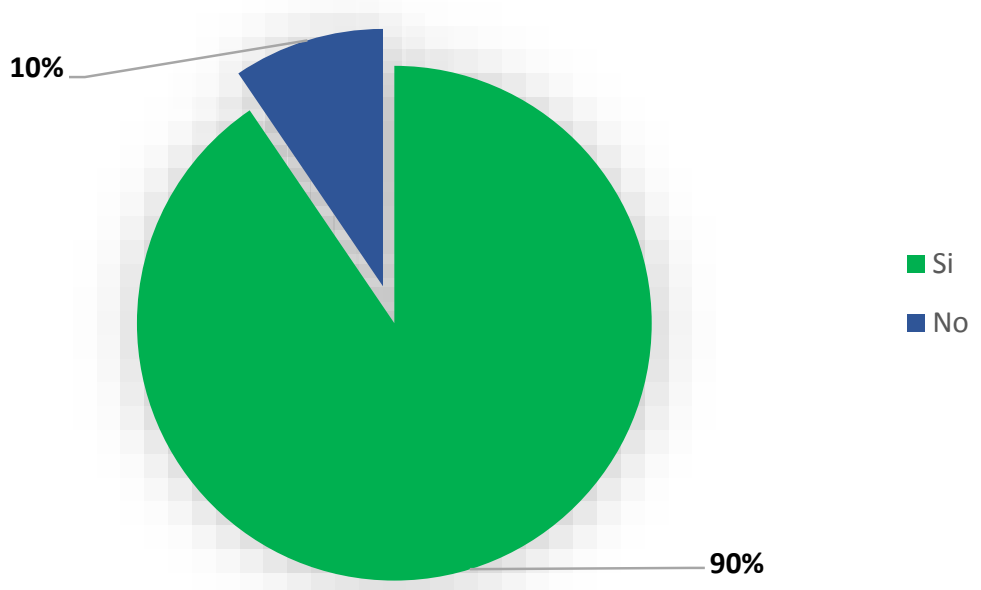

Figura 3. Cumplimiento de los términos en la tramitación de la acción de protección. Fuente. Encuestas realizadas a abogados en libre ejercicio

Del análisis de 32 causas (acciones de protección) ingresadas en el primer semestre del 2019 en una Unidad Judicial de Loja, tomando como referencia la duración de 10 días de acuerdo a la LOGJCC, se organizó la tabla 1, en donde se agrupan las causas por intervalos de tiempo.

\section{Tabla 1}

Duración de procesos

Rango (No. De días)

Cantidad de procesos

Porcentaje despachados

\begin{tabular}{ccc}
\hline Entre 1 - 10 días & 0 & 0 \\
Entre 11 -30 días & 17 & $53,1 \%$ \\
Entre 31-50 días & 11 & $34,4 \%$ \\
Entre 51 -70 días & 1 & $3,1 \%$ \\
Entre 71 - 90 días & 1 & $3,1 \%$ \\
Más de 90 días & 2 & $6,3 \%$
\end{tabular}

Fuente. Sistema SATJE Consejo de la Judicatura 
De los datos expuestos se puede constatar que el $53.12 \%$ de los procesos revisados tienen una duración entre 11 y 30 días, el $34.4 \%$ se desarrolla entre 31 y 50 días y un $6.3 \%$ se tramita en más de 100 días. Cabe destacar que con los datos observados se verifica que ningún proceso se ajusta al rango de 1 a 10 días; es decir, la tramitación de las acciones de protección no se enmarca a los tiempos establecidos en la ley.

De las evidencias expuestas, se verificó que existe un incumplimiento de los términos establecidos para la tramitación de la acción de protección, lo que ocasiona la vulneración del derecho al debido proceso y tutelas efectivas consagradas en la Constitución y con esto que los titulares de derechos no cuenten con un proceso inmediato y efectivo.

A partir de estos resultados, en la investigación se considera pertinente diseñar un protocolo que garantice el cumplimiento de los términos en el procedimiento de la acción de protección, dirigido a Jueces con competencia en materia constitucional.

\section{PROPUESTA}

A partir de los de los resultados obtenidos se ha verificado que los términos dentro de la tramitación de la acción de protección, no son aplicados de manera efectiva por parte de los órganos jurisdiccionales competentes, vulnerando así el derecho al debido proceso y tutela efectiva; así como también inobservando el objeto mismo de la acción de protección que es el amparo directo y eficaz de los derechos trasgredidos y que necesitan protección inmediata. En virtud se diseña un protocolo para el cumplimiento de los términos en la tramitación de la acción de protección, que permitirá con base en la normativa vigente que los jueces y juezas apliquen de manera inmediata y efectiva esta garantía constitucional. 

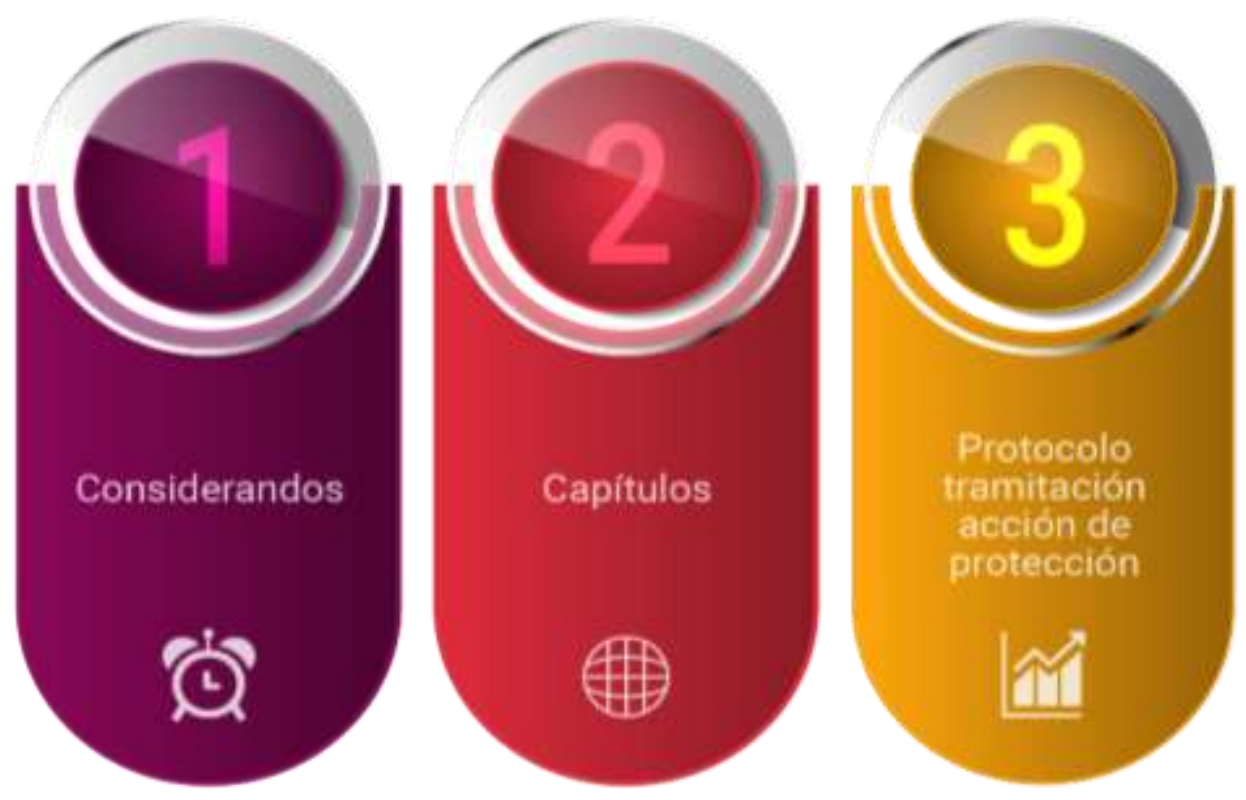

Figura 4. Esquema de la propuesta de protocolo

\section{Resolución}

\section{El Pleno del Consejo de la Judicatura}

\section{Considerando:}

Que, el Consejo de la Judicatura es el órgano de dirección, régimen, control de la Función Judicial conforme lo prescribe el artículo 178 del texto constitucional;

Que, la norma constitucional ecuatoriana en el artículo 75, establece: Todo individuo gozará de un proceso justo, objetivo e inmediato donde predomine la tutela eficaz de los derechos, de ningún modo se podrá negar el acceso a la justicia. La inobservancia a las de las disposiciones judiciales será sancionada por la ley;

Que, el texto constitucional determina en el artículo 76: En todo proceso en el que se establezcan derechos y deberes de cualquier orden, se asegurará el derecho a un proceso justo: 1) Se cumplirá con la normativa vigente y se garantizara el derecho de las partes dentro de un proceso justo, en el ámbito jurisdiccional o administrativo. 
Que, el texto constitucional en su artículo 88 indicada: La acción de protección tiene como propósito el amparo inmediato y efectivo de los derechos de las personas.

Que, los numerales 1 y 5 del texto ibidem, señala que tendrán las siguientes atribuciones del Pleno del Consejo, así como las que prescriba la ley: 1. Delimitar y elaborar las estrategias para la mejora y progreso del sistema judicial ecuatoriano; y, 5. Vigilar por la probidad y eficacia de la Función Judicial;

Que, el artículo 172 de la norma constitucional prescribe: Violaciones procesales. Las autoridades jurisdiccionales dirigirán los procesos jurisdiccionales con observación a la normativa vigente nacional e internacional. Las funcionarias y funcionarios judiciales, que incluyen a las autoridades jurisdiccionales, deberán realizar sus actividades con la debida diligencia establecida como principio constitucional; la demora injustificada estará bajo su responsabilidad, es decir, estos asumirán la responsabilidad por el daño ocasionado por incurrir en demora, descuido o negar el acceso a la justicia;

Que, el artículo 25 de la Convención Americana sobre Derechos Humanos o Pacto de San José, determina: A todo ser humano se le garantizará un proceso justo, inmediato y sin dilaciones ante las jurisdicciones competentes de la justicia ordinaria o especializada; que aseguren que ningún hecho u omisión vulnere los derechos constitucionales que le corresponden y que son amparados en la normativa nacional e internacional vigente.

Que, la Asamblea Nacional del Ecuador, mediante Suplemento del Registro Oficial No. 52, de 22 de octubre de 2009, expidió la Ley Orgánica de Garantías Jurisdiccionales y Control Constitucional;

Que, el artículo 39 de la LOGJCC establece la acción de protección tiene como propósito el amparo inmediato y efectivo de los derechos de las personas;

Que, la LOGJCC establece en el artículo 22.2: violaciones procesales, 2. Si las servidoras y servidores jurisdiccionales realicen incumplimiento durante el trámite, será catalogado como falta gravísima y se comunicará al Consejo de la Judicatura; y, 3) Si las inobservancias al procedimiento o tiempos prescritos en esta ley vienen de las propias juezas o jueces, los afectados están en el derecho de presentar la queja las autoridades administrativas de la Judicatura conforme al del Código Orgánico de la Función Judicial; 
Que, el artículo 3 del Código Orgánico de la Función Judicial, indica: las autoridades de la Función Judicial, en ejercicio de sus funciones, deberán establecer estrategias dentro del ámbito de sus funciones que permitan fortalecer a la institución y de esta manera ofrecer una atención efectiva, eficaz e inmediata en correspondencia a las necesidades de los usuarios.

Que, de acuerdo a la norma ibidem a las autoridades de la Función Judicial les corresponde de acuerdo al artículo 264: 10. Expedir toda la normativa de régimen interno, observando las normas constituciones y demás leyes que para el efecto sean aplicables a fin de establecer reglas de actuación, manejo, dirección de la institución, así como instaurar el régimen disciplinario, lo que permitirá la transparencia y mejoramiento de la Función Judicial.

En ejercicio de sus atribuciones constitucionales y legales, por unanimidad de los presentes.

\section{Resuelve:}

\section{Aprobar el protocolo para el cumplimiento de los términos en la tramitación de la acción de protección \\ Capítulo I}

\section{Principio de independencia, integridad y celeridad}

Artículo 1.- Ámbito de aplicación. - Las disposiciones en el presente protocolo se aplican a todas las juezas y jueces de primera y segunda instancia competentes en materia constitucional. Las personas que están sujetas a la aplicación de este protocolo deberán cumplir sus disposiciones.

Artículo 2.- Principios rectores. - Las juezas y jueces deberán llevar a cabo las tareas de la función judicial de forma imparcial, competente y diligente.

Artículo 3.- Cumplimiento con la ley. - Las juezas y jueces deberán cumplir con la ley, incluido el presente protocolo. 


\section{Capítulo II}

\section{De las actividades judiciales}

Artículo 4. - Tratamiento preferente e inmediato de la acción de protección. La jueza o juez que por sorteo le corresponda conocer una acción de protección, deberá darle atención preferente e inmediata sobre las demás causas que este en conocimiento, respetando los preceptos legales establecidos y de ser necesario activará todos los medios físicos y telemáticos para su cumplimiento.

\section{Artículo 5.- Cumplimiento de términos referentes a las garantías jurisdiccionales.}

La jueza o juez deberá llevar a cabo las tareas judiciales de forma eficiente y diligente al conocer una acción de protección y deberá tomar los siguientes lineamientos de manera obligatoria:

a) Una vez presentada la petición, la autoridad competente tendrá como tiempo máximo veinticuatro horas para aceptar el trámite;

b) Las citaciones y notificaciones deberán realizarse dentro de las 24 horas siguientes de avocado conocimiento, y se deberán aplicar los medios físicos y telemáticos como correo electrónico, casillero electrónico para la notificación correspondiente;

c) La audiencia deberá señalarse máximo en 72 horas siguientes de la aceptación a trámite. Para el desarrollo de la misma podrán utilizarse los medios necesarios, así como medios telemáticos conforme a la resoluciones y protocolos establecidos por el Pleno del Consejo de la Judicatura para el efecto.

d) En el caso de que la jueza o juez requiera la práctica de prueba complementaria, se deberá establecer como término máximo 8 días.

e) La jueza o juez una vez que formen criterio, deberá dictar la sentencia en la misma audiencia, deberá de manera improrrogable notificarla por escrito dentro de las 48 horas siguientes.

f) De pronunciarse de forma verbal en la audiencia o presentado por escrito la apelación luego de los tres días hábiles conforme lo dispone la ley, la jueza o juez concederá el recurso propuesto dentro de las 24 horas siguientes una vez ejecutoriado la auto concesión del recurso. Asimismo, deberá ser remitida a la oficina de sorteo el mismo 
día para radicar competencia en la Corte Provincial.

\section{Disposiciones finales}

Primero: Los órganos administrativos nacionales y provinciales serán los responsables del cumplimiento de esta resolución.

Segunda: Este protocolo tendrá validez jurídica partir de su aprobación, sin perjuicio de su divulgación en el Registro Oficial.

Dado en el Distrito Metropolitano de Quito, en la sala de reuniones del Pleno del Consejo de la Judicatura, el treinta de mayo de dos veinte.

\section{DISCUSIÓN}

Del estudio realizado se determina que el derecho a un proceso justo y una defensa eficaz, son derechos constituciones que se encuentran intrínsecos en los procedimientos judiciales y administrativos que permiten que los procesos se desarrollen sujetados a los parámetros establecidos en la constitución y la ley, así como también, al acceso a una justicia imparcial, rápida y sin dilaciones. De igual manera, la acción de protección es una garantía jurisdiccional que permite la protección inmediata y eficaz de los derechos humanos que sean lesionados o quebrantados y que se encuentren reconocidos en la normativa vigente.

Cabe considerar, por otra parte que mediante los resultados obtenidos en la encuesta aplicada y del análisis de los datos obtenidos en la revisión de las causas (acciones de protección), se concluye que existe incumplimiento de los términos en la tramitación de la garantía jurisdiccional antes indicada; $y$, de este modo se vulneran de forma directa los derechos constitucionales de la tutela efectiva y del debido proceso, puesto que las diferentes actividades procesales tienen un retraso demasiado elevado con referencia a los términos que se plantean en la LOGJCC. Por consiguiente, no se está dando la protección debida a los derechos de las personas conforme lo manda la constitución y los tratados internacionales de derechos humanos. 
Las afirmaciones anteriores han permitido establecer la necesidad de la elaboración de un protocolo para el cumplimiento de los términos en el procedimiento de la acción de protección que permita que las juezas y jueces constitucionales competentes para la tramitación cumplan en debida forma los tiempos establecidos en la ley; de esta manera, se dará un trato preferencial a estos procesos que tutelan y protegen los derechos que por mandato constitucional le corresponden a cada persona.

\section{FINANCIAMIENTO}

No monetario.

\section{AGRADECIMIENTO}

Al personal de la Unidad Judicial de Loja por apoyar la realización del proyecto investigativo.

\section{REFERENCIAS CONSULTADAS}

Arichavala- Zúñiga, J. C., Narváez- Zurita, C. I., Guerra-Coronel, M. A., \& Erazo-Álvarez, J. C. (Diciembre de 2019). La acción de protección: ¿Una vía idónea para tutelar derechos constitucionales? [Action of protection: ¿An ideal way to protect rights?]. Fundación Koinonia. Obtenido de https://n9.cl/9m93

Asamblea Constituyente de Bolivia. (25 de enero de 2009). Constitución Política del Estado plurinacional de Bolivia. [Political Constitution of the Plurinational State of Bolivia]. Garantías Jurisdiccionales y Acciones de Defensa. El Alto, Bolivia. Obtenido de https://n9.cl/gq05v

Asamblea General de las Naciones Unidas. (10 de Diciembre de 1948). Declaración Universal de Derechos Humanos. [Universal Declaration of Human Rights]. Declaración Universal de Derechos Humanos. París, París, Francia. Obtenido de https://url2.cl/bix9J

Asamblea Nacional. (21 de Septiembre de 2009). Ley orgánica de garantías jurisdiccionales y control constitucional. [Organic law of jurisdictional guarantees and constitutional control]. Garantías jurisdiccionales de los derechos constitucionales. Quito, Pichincha, Ecuador: Registro Oficial Sumplemento 52. 
Asamblea Nacional. (22 de octubre de 2009). Ley orgánica de garantías jurisdiccionales y control constitucional. [Organic law of jurisdictional guarantees and constitutional control]. Normas Generales. Quito, Pichincha, Ecuador: Registro oficial suplemento 52.

Asamblea Nacional Constituyente. (25 de Mayo de 1967). Constitución Política del Estado Ecuatoriano. [Political Constitution of de Ecuadorian State]. Constitución Política del Estado Ecuatoriano. Quito, Pichincha, Ecuador: Asamblea Nacional Consituyente. Obtenido de https://url2.cl/wMdwH

Asamblea Nacional Constituyente. (04 de julio de 1991). Constiución Política de Colombia. [Political Constitution of Colombia]. De los derechos, las garantías y los deberes. Bogotá, Colombia: Gaceta Constitucional 114. Obtenido de https://n9.cl/gh1s

Asamblea Nacional Constituyente. (18 de Junio de 1998). Constitución de Política de la República del Ecuador 1998. [Constitution of Politics of the Republic of Ecuador]. Constitución de Política de la República del Ecuador 1998. Quito , Pichincha, Ecuador: Asamblea Nacional Constituyente. Obtenido de https://url2.cl/3becH

Asamblea Nacional Constituyente. (20 de octubre de 2008). Constitución de la República del Ecuador. [Constitution of the Republic of Ecuador]. Garantías Constitucionales. Montecristi, Manabí, Ecuador: Registro Oficial 449.

Ávila, R. (2012). Los derechos y sus garantías. Ensayos críticos [Rights and Guarantees Critical Essays]. Quito, Pichincha, Ecuador: Centro de Estudios y Difusión del Derecho. Obtenido de https://url2.cl/stwjh

Bravo-Núñez, A. d., Narváez-Zurita, C. I., Vázquez-Calle, J. L., \& Erazo-Álvarez, J. C. (2020). Reparación integral de la Corte Interamericana de Derechos Humanos: Sentencia Extraordinaria de Protección. [Comprehensive reparation of the InterAmerican Court of Human Rights: Extraordinary Protection Judgment]. Iustitia Socialis, 591. doi:http://dx.doi.org/10.35381/racji.v5i8.592

Calle, E. (2010). La acción de protección. [The Protection Action]. La acción de protección., 10. Cuenca, Azuay, Ecuador. Obtenido de https://n9.cl/frti

Congreso Constituyente Democrático. (29 de diciembre de 1993). Constitución Política del Perú. [Political Constitution of Peru]. De las garantías constitucionales. Lima, Perú. Obtenido de https://n9.cl/809x0 
Gray, A. (01 de 01 de 2000). El debido proceso en la constitución. [Due process in the Constitution]. Recuperado: https://url2.cl/EJ8gk. IURIS DICTIO, 1, 4. doi:https://doi.org/10.18272/iu.v1i1.470

IX Conferencia Internacional Americana. (02 de Mayo de 1948). Declaración Americana de los Derechos y Deberes del Hombre. [American Declaration of the Rights and Duties of Man]. Deberes. Bogotá, Bogotá, Colombia: Organización de Estados Americanos. Obtenido de https://url2.cl/p9u7W

Jaramillo, H. (2014). La justicia constitucional. Las acciones de protección. [Constututional justice, protection actions]. Loja: Grafimundo.

López, A. (01 de Enero de 2018). La acción de protección su eficacia y aplicación en el Ecuador. [Protective action, its effectiveness and application in Ecuador]. Dialnet plus, 11. doi:https://doi.org/10.23857/dom.cien.pocaip.2017.4.1.enero.155-177

Ministerio Secretaria General de la Presidencia. (21 de octubre de 1980). Consitución Política de la República de Chile. [Political Constitution of the Republic of Chile]. Derechos y Deberes Constitucionales. Santiago, Chile. Obtenido de https://n9.cl/8uqh

Montaña, J., \& Porras, A. (2012). Apuntes de derecho procesal constitucional [Notes on constitutional procedural law]. Quito: Centro de estudios y difusión del derecho constitucional.

Organización de los Estados Americanos. (22 de Noviembre de 1969). Convención Americana sobre Derechos Humanos o Pacto de San José de Costa Rica. [American Convention on Human Rights or Pact of San Jose de Costa Rica]. Deberes de los estados y derechos protegidos. San José, San José, Costa Rica: Departamento de Derecho Internacional. Obtenido de https://url2.cl/SktFe

Quintana, I. (2016). La acción de protección. [The protection action]. Quito, Pichincha, Ecuador: Corporación de estudios y publicaciones.

Sentencia 045-13-SEP-13., Caso 0499-11-EP (Corte Constitucional del Ecuador 31 de julio de 2013). Obtenido de https://n9.cl/jn5j

Sentencia 06-10-SAN-CC., 0107-09-AN (Corte constitucional para el periodo de transición 16 de diciembre de 2010). Obtenido de https://n9.cl/d1jw

Sentencia 080-13-SEP-CC., Caso 0445-11-EP (Corte Constitucional del Ecuador 09 de octubre de 2013). Obtenido de https://url2.cl/VMvjf 
Sentencia 102-13-SEP-13., Caso No. 380-10-EP (Corte Constitucional del Ecuador 04 de diciembre de 2013). Obtenido de https://n9.cl/00qnf

Sentencia 204-12-SEP-CC., Caso No. 1247-10-EP (Corte Constitucional para el período de transición 08 de mayo de 2012). Obtenido de https://n9.cl//7bu

Sentencia 292-SEP-CC., Caso No. 0734-13-EP (Corte Constitucional del Ecuador 16 de septiembre de 2016). Obtenido de https://n9.cl/12dk

Sentencia 364-16-SEP-CC., Caso No. 1470-14-EP (Corte Constitucional del Ecuador 15 de noviembre de 2016). Obtenido de https://n9.cl/t6rgy

Storini, C. (2017). Carta Magna y Nuevo Constiucionalismo Latinoamericano ¿ Ruptura o Continuismo?. [Magna Carta and New Latin American Constitutionalism Rupture or Continuism? Quito: Corporación Editora Nacional. 